\title{
Emotional and Relationship Dynamics between HIV Sero- Discordance and Concordance Couples: A Narrative Literature Review and Theoretical Framework
}

\author{
Amani Mwakalapuka', Ipyana Mwampagatwa², Theodora Bali ${ }^{3}$, Masumbuko Mwashambwa ${ }^{4}$, \\ Stephen Kibusi ${ }^{5}$, Tumbwene Mwansisya ${ }^{6}$,* \\ ${ }^{l}$ Department of Social science, College of Humanities and Social Sciences, Sokoine University of Agriculture, \\ P.O Box 3038, Morogoro, Tanzania \\ ${ }^{2}$ Department of Obstetrics and Gynaecology, School of Medicine and Dentistry, The University Of Dodoma, \\ P.O Box 395, Dodoma, Tanzania \\ ${ }^{3}$ Faculty of Humanities and Education, St John's University of Tanzania, P.O. Box 47, Dodoma, Tanzania \\ ${ }^{4}$ Department of Surgery, School of Medicine and Dentistry, the University Of Dodoma, P.o Box 395, Dodoma, \\ Tanzania \\ ${ }^{6}$ Department of Psychiatry and Mental health, School of Nursing and Midwifery, the Aga Khan University of \\ East Africa, P.O Box 125, Dares salaam, Tanzania
}

*Corresponding Author: Tumbwene E. Mwansisya, Department of Psychiatry and Mental health, School of Nursing and Midwifery, the Aga Khan University of East Africa, P.O Box 125, Dares salaam, Tanzania, E-mail: mwansisya@yahoo.co.uk

\begin{abstract}
Tanzania is among the countries with high prevalence of HIV prevalence in the World. Despite the fact that the epidemic has been, and still is a threat to persons of all ages, recent studies have suggested that most new infections occur among couples in stable relationships. Infected couples are categorised into two: the positive concordant, where both the partners are HIV positive; and sero-discordant couples, where one partner is HIV positive while the other is negative. Recently, researchers and many other stake-holders working on the HIV/AIDS epidemic have given a remarkable attention to this astonishing reality. For instance one study in East and Southern Africa indicates that there are great variations of discordancy varying from $36 \%$ to $85 \%$, with an overall rate of $49 \%$.

HIV couple sero-discordancy is responsible for varied levels of psychological distress including heightened levels of anxiety, poor emotional adaptation and increased or excessive substance use, most often coupled with exclusion and social isolation within family and in the neighbourhood. However, to date the influence of sero-discordancy on family and couple relationship functioning and how it differs from that among concordant couples remains elusive.

Discordancy have been associated with more difficulties as compared to the seroconverted couples, these include relationship and emotional disturbances, sexual contact distancing, marital separation and disruptions. The Lazarus and Folkman's (1984)'s Transactional Model can be helpful in understanding individuals with HIV discordancy on their emotional response, coping strategies and the ultimate decisions towards their marital relationships fate.
\end{abstract}

Keywords: Couple sero-discordancy, HIV/AIDS, Theory, Emotional problems, psychosocial problems, Literature review.

\section{BACKGROUND}

For over three decades since its discovery in 1981, HIV/AIDS has continued to be a major public health concern affecting, both, social and economic development in most developing countries, especially, the Sub-Saharan Africa. In Tanzania, for example, the current survey found that 5.1 percent of those tested were HIV positive. Despite the fact that the epidemic has been, and still is a threat to persons of all ages, 
recent studies have suggested that most new infections occur among couples in stable relationships (Bishop and Fareit, 2010). Thus, some couples are infected while others are not. Infected couples are categorised into two: the positive concordant, where both the partners are HIV positive; and sero-discordant couples, where one partner is HIV positive while the other is negative.

High prevalence of HIV-discordancy in the world is not new. However, it was not until late 1990's when studies from different parts of the world started to seriously document pervasiveness of couples who lived along with a different sero-status partner. Recently, scientists and many other stake-holders working on the HIV/AIDS epidemic have given a remarkable attention to this astonishing reality. Thus, today, many publications, both academic and of social welfare, have tried to substantiate the prevalence of discordancy, factors leading to discordancy, and some problems that these couples go through in their daily life, factors leading to discordancy, unprotected sex between the partners or lovers and unfaithfulness or promiscuity.

Despite all the efforts done already, much remains unknown, particularly on the emotional and psychosocial effects infected couples endure in either concordant or discordant relationship, factors that influenced discordant couples' ultimate decisions on their marital ends, and the likelihood of their relationship functioning.

\section{METHODS}

\subsection{Eligibility Criteria of the Studies Included in the Review}

Studies were selected for inclusion in this review if they met the following criteria

- They included any measure of Concordant or discordant of HIV status in partners.

- The sample comprised participants aged 18 years and older.

- They were published in a peer reviewed journal in the English Language

- The studies needed to be conducted in a resource-limited setting, defined as low or middle-income countries.

Articles were immediately excluded if they did not involve HIV discordancy or concordancy, involved children or adolescent, were not published in English.

\subsection{Search strategy for the identification of relevant studies}

A broad search strategy for potential articles was used in order to include all relevant studies. Electronic searches of Medline, EMBASE, PsycINFO, Web of Science with subject headings including HIV status, HIV discordancy, HIV discordancy, HIV and couples, HIV Sero-status determinants, HIV discordancy and emotions. These words were used alone or in combination including $H I V$ AND discordanc* or concorda* AND (couple* OR partner*). We also searched the bibliographies of the retrieved studies and published or unpublished relevant articles. Two authors (AAM and TEM) independently reviewed the articles to determine inclusion. Disagreements were resolved by consensus. Each article was analyzed to determine the sample characteristics, study setting, definition of and prevalence of discordance or concordancy, outcomes of their sero-status disclosure, and emotional and relationship functioning after disclosure of their HIV status.

\subsection{Factors Associated with Couple Sero- discordancy}

Determinants of couple discordancy are an increasingly encountered phenomenon in research and clinical management of HIV. A number of factors have been established to explain this occurrence. Primary to this occurrence are biological factors. Evidence from various studies, (de Walque, 2006; Wilde, 2002; Melo et al., 2008) indicate that when an HIV infected partner has a small viral load there are small chances for their seronegative spouse to be infected. More recent studies have further demonstrated that heterosexual transmission is a function of plasma viral load (Kumarasamy et al., 2010; Chavan et al., 2014). While many studies support this claim, there are reports in some other studies that indicate that partner's low viral load was not the cause of resistance to HIV, of the uninfected matched spouse (Louisirirotchakul et al, 2001). They also suggest the role of the less known genetic factors as responsible for persons' resistance to HIV in a discordant relationship. Some studies indicate that some individuals are seen to be genetically resistant to HIV infection (Novembre, Galvani, and Slatkin, 2005; Cohn 
and Weaver, 2006; Pancino et al, 2010). Presence of broadly studied genes and their mutations, such as Chemokine Receptors (CCR5 and other variants) and Killer Immunogloblin-like Receptors (KIR) has been associated with some individuals' susceptibility or resistance to contracting the HIV and disease progression (Michael, 1997; Kumar et al., 2006; Chavan et al, 2014; Zwolinska et al., 2016). Geographic mapping, however, suggest that such mutation as CCR5 are more prevalent in the northern hemisphere, particularly northern Europe and some parts of Asia Novembre, Galvan and Slatkin, 2005). These, however, may not adequately explain the pervasiveness of discordance in sub-Saharan Africa, where such mutations are said to be rare. So, it is most likely that many cases of sero-discordancy the Region are not genetically determined; they are thus temporal, leaving the negative couple susceptible to contracting the virus. These factors are both immunological and virological, thereby, the viral subtype, stage of infection, shared human leukocyte and a few more are seen to contribute to negative couples' susceptibility or resistance to HIV infection. Nevertheless, their actual contribution is not known yet (Bruyn, Badenzi, Dladla \& Gray, 2006).

Male circumcision is yet another factor. A report from a South African based HIV clinic indicates that most uncircumcised male partners were much more susceptible to contracting the virus even though reasons behind this are not very clear yet (Bruyn, Badenzi, Dladla \& Gray, 2006; WHO/UNAIDS, 2013). A number of randomised trials (Gray et al., 2007; Desgreesdu- Lou and Orne-Gliemann, 2008; Mackelprang et al., 2012; Kimanga 2014) have continued to bring in evidence of the reduced HIV transmission rates among male partners who are circumcised. The implication is that certain couples may have sustained the discordant serostatus because the circumcised male partner in a relationship is either less likely to infect his female partner or he is less likely to be infected by his positive female partner. Other factors for couple discordancy include prior exposure to sexually transmitted infections such as HSV-2 which has closely been associated with HIV-1 cases. Despite the evidence to minimise HIV transmission, the actual contribution of male circumcision to couple HIV discordancy is yet to be substantiated.

\subsection{The Magnitude and Sex Ratio of Sero- discordancy}

Generally, as suggested by Bishop and Foreit, (2010), HIV prevalence among couples is similar to that in the general population. Many other studies, however, suggest great variations in the proportions of discordancy to that of concordancy. In Thailand, discordance rate is estimated at 58\% (Rojanawiwat et al., 2001), whereas, in India, current studies indicate a $54.6 \%$ discordant rate (Mehra et al., 2015) from $40 \%$ in the previous studies (Marfatia et al., 2013). A major study by Lingappa et al., (2008) in twelve partner sites in East and Southern Africa indicates great variations of discordancy the Region, varying from $36 \%$ to $85 \%$, with an overall rate of $49 \%$. Chemaitelly et al. (2012)'s meta-analysis of DHS data from sub-Saharan Africa suggests that where HIV prevalence is less than ten percent, the vast majority in stable relationships were discordant, ranging between $48.4 \%$ and $87.8 \%$ (Chemaitelly, 2012). The study further suggests that countries with HIV prevalence rates greater than ten percent had discordancy ranging between $36.3 \%$ and 58.5 $\%$. Despite the variations observed in these and other studies, it remains universal that the proportion of couples in stable relationships who are discordant is undeniably substantial, thus, the need for effective prevention strategies of the negative partner and promotion of wellbeing among both the partners. This has pushed the international community to strategise on preventive measures. Thus, in 2013, the WHO offered guidelines for sero-discordant couples on issues related to couple counselling, ARV treatment and Pre-Exposure prophylaxis, to mention just a few, all geared to promote prevention efforts against new infections among negative discordant couples.

In a study in seven African countries including Tanzania, Uganda, Kenya, Cameroon, Botswana and Lesotho, de Walque, (2006) observes that the proportion of couples who are serodiscordant is higher than that in which both couples are positive with the exception of Swaziland. De Walque, (2006) observes that the proportion of male partners who are seropositive in Lesotho is twice as high as that where the woman is sero-positive. The same study indicates that in Kenya and Tanzania, the proportion of sero-discordant couples is at least twice as high as that of sero-concordant couples. Contrarily, significantly higher proportions of 
couples $(60 \%)$ where the female is the infected partner is observed in Kenya. A study in Quang Ninh Province in Vietnam indicates that the proportion of discordant couples in the study was $58 \%$, with discordancy rates being higher among men (71\%) than among women (18\%), (Tam et al., 2016). The marked gender differences may have a lot to do with socioeconomic and socio-cultural dynamics in these regions which are yet to be substantiated. In any case, the magnitude and sex suggests that the need for preventive efforts against new HIV infections and sexual health focus among serodiscordant couples cannot be overemphasised.

\subsection{HIV/AIDS and the Marital Life}

Based on the socio-cultural relations in Tanzania, most marital relations start at age 1840 which is the sexually active group. While some studies such as Idele et al., (2014) indicate that young people are the most vulnerable as far as HIV infection is concerned, evidence from carious studies suggest that many adults, especially married couples, are at a higher risk of being infected (UNAIDS, 2013; Kaiser, 2011; Chemaitelly, Awad and Abu-Raddad, 2014).

The 2011-2012 Malaria and AIDS Indicators Survey report reveals a significant difference in HIV prevalence based on marital status. While the never married individuals had a prevalence rate of $3.3 \%$ and $1.2 \%$ among women and men, respectively, couples, either married or cohabiting, had an average rate of 5.2 in women and 5.4 in men. The separated or divorced couples had higher HIV prevalence rates (15.2 in women, 8.9 in men) and the highest rates were observed among the widows/widowers (24.7 in women, 27.9 in men) (TACAIDS, 2013). Introduction of HIV infection in a couple, and the resulting concordancy and seroconversion have been associated with emotional and psychosocial challenges between the partners (Malamba et al., 2005). This has increased their emotional disarray in discordant relationships (Reshmi \& Sekar, 2011), and has also elevated the uninfected partners' susceptibility of contracting HIV (Mujugira et al., 2011). Couples, therefore, in whatever kind of sexual relations, present a focal point for prevention and treatment effort against HIV/AIDS at community, national and global levels.
2.6 New HIV-Infections and Susceptibility of Sero-conversion among Sero-Discordant Couples

Quite a number of studies indicate that most HIV infections occur in stable relationships (Allen et al., 2007; Chomba, 2008; Matovu, 2010; Mujugira et al., 2011; UNAIDS, 2014). Dunkle et al., (2008) estimate two thirds of new infections in Lusaka-Zambia as occurring in stable unions. Available Demographic and Health Surveys (DHS) and AIDS Survey Index (ASI) from various countries continue to indicate large proportions of new HIV infections as occurring in stable unions (WHO, 2013), thus increasing the numbers of HIV concordancy.

There two views regarding HIV discordancy: the retrospective and prospective views. In the first view, perceives discordancy by looking back in time to focus on its origin (Champredon, Bellan and Dushoff, 2013). In this view, a high level of discordancy is perceived as resulting from HIV infection external to the couple. For instance, Lurie at al., (2003), in a study involving migrant workers in South Africa, suggests that migrant men acquire HIV infection in which they work, then bring it to their partners back in their villages, thus the introduction of discordancy in their relationships. I relation to the prospective view, discordancy is viewed as a potential risk factor for infection of the uninfected partner (Allen et al., 2007; Grabowski et al., 2014). Essentially, both the views help conceptualise, first, the contribution of partner's infection as initially external to the couple during or prior to their union. Second, they serve to explicate the propensity of sero-conversion that the negative partner is constantly exposed to in a discordant relationship. In this view, introduction of HIV to a partner in a stable sexual relationship presents potential susceptibility to infection of the negative partner in a discordant relationship (Chemaitelly et al., 2014).

Carpenter et al., (1999), in their seven year study of 2,200 adults in rural Uganda who tested their HIV status once annually, establish that sero-conversion was responsible for new infections among couples in union. A more revealing study is that by Trask et al., (2002) on molecular analysis of seroconverted discordant couples' blood. The study substantiates that out of all the seroconversions, only $13 \%$ were intra- 
couple, while $87 \%$ were significantly intercouple. A recent study by Campbell, (2011) on viral linkage, involved 3,408 discordant couples, in which, 155 couples seroconverted. The study further reveals that $71.5 \%$ of the new infections were confirmed to be inter-couple, $26.5 \%$ were not linked, while $2 \%$ were indeterminate. The large of proportion that are linked with HIV infections among sero-converting partners confirm the claim that most new HIV infections occur in stable unions.

Some studies have attempted to approximate the probability of HIV transmission among heterosexual couples. Two studies in RakaiUganda estimate an average of $0.0011 /$ coital act (Gray et al., 2001) and 0.0012/coital act (Wawer et al., 2005). In Zambia Hira et al., (1997) estimates transmission rate at $0.0009 /$ coital act. These rates may indicate that the probability of a partner to catch HIV from their spouse is low. However, Guthrie, (2007)'s study on discordant couples sex-specific HIV transmission rate of 1.2 to 19 per person year further indicates a significant health threat that calls for practical intervention strategies among couples with unlike HIV statuses.

\subsection{Child-Bearing among Infected Couples}

Starting a family and or having healthy children of their own are among the major concerns infected couples have (Marfatia et al., 2013). In the traditional African way, child bearing is as important as marriage itself and the one and only natural way to conceive is sexual intercourse. Chen et al., (2001) report, in a study involving $1421 \mathrm{HIV}$ infected adults, that $28 \%$ to $29 \%$ of these adults indicated a strong desire to have children of their own. Women needed children to regain their sense of womanhood and sexuality, and to give purpose to life. Conceiving and giving birth to an uninfected baby, has become particularly challenging among infected couples. This is exacerbated by the fact that unprotected sexual contact with infected partner is the main way by which HIV is contracted in Sub-Saharan Africa (UNAIDS, 2008). Infected couples are thus left with limited choices, some of which are too expensive for ordinary people.

Semen produced by a man during copulation contains together with other things, the male reproductive cells-Spermatozoa. These cells, which make only about 10 percent of the semen, may thinly be responsible for HIV transmission from a positive discordant male couple to the negative female partner with the risk of seroconversion ranging from 0.1 to 0.2 percent in a single act of unprotected sexual contact (Mastro, 1996). In their study involving 198 female couples cohabiting with sero-positive German men, Rockstroh, Ewig, Bauer, Luchters, Oldenburg, Bailly et al., (1995) observe that ten percent of the sero-negative couples became infected by their partners and acquired their spouses' positive sero-statuses.

Recent studies indicate that chances of a discordant male couple to infect his negative female partner are one in ten for less than ten unprotected sexual contacts, and around one in four after two thousand unprotected sexual contacts (Downs \& De Vincenzi, 1996). Other studies indicate 0.0015 chances per coital act (Wawer, 2005). No matter how minimal the rate may seem, chances are the negative partner is constantly exposed to the risk of HIV contraction from their spouse. To minimize the chances of catching HIV from the positive discordant male couple by the negative female couple who seeks to find children with an infected partner, studies suggest attempt of unprotected sexual contact during ovulation (Mandelbrot et al., 1997). Out of the ninety two sero-discordant couples who were involved in the study of positive male couples against their negative spouses, only four women were seroconverted; two in third trimester of pregnancy, and two in the period following delivery (Mandelbrot et al., 1997). In another study involving 28 discordant couples in Cardiff, UK, 26 children were born over a period of 15 years, and no sero-conversion was reported (Ramsahoye, Collins, Davies \& Walkers, 1998). Again, at the Royal Free Hospital in London, UK, 14 discordant couples gave birth to 19 children; sero-conversion was reported for only one female partner, while all the children were negative (Yee et al.,1999).

Recent studies, however, revealed that unprotected sexual contact among child-seeking discordant couples during ovulation may only apply to men with normal correlation between their blood viral loads to semen viral load, the latter of which is normally 10 times lower than the former. Exception is among some male discordant couples whose semen viral loads even exceed their blood viral loads (Quinn et al., 2000; Wilde, 2002). Viral suppression and sperm washing are also the other methods. 
Positive female couples are likely to infect their unborn babies normally at birth (UNAIDS, 2007). To minimize these chances, a centre for HIV/AIDS Research at Muhimbili National Hospital in Tanzania is running a special programme to help such couples have a safe motherhood. These mothers are given special treatment during pregnancy and at delivery, which helps the baby to be delivered uninfected. In their study on HIV-1 Transmission risk in African countries (Mugo, et al., 2011) concluded that there is an increased risk of HIV acquisition among pregnant negative women and increased transmission risk to men during pregnancy, which is also supported by Brubaker et al.,(2011) whose study revealed that chances of re-conversion almost doubled in couples where pregnancy occurred (5.9\% vs 10.8\%). Child-seeking women are at even a higher risk of transmitting and or getting infected of HIV. Having little or no control over their sexual negotiations often push them to the dilemma of choice between prevention against HIV infection and performing their reproductive roles.

\subsection{Emotional Experiences of Sero- discordant Couples in Marital Relations}

HIV couple sero-discordancy, depending on the couples' knowledge, skills, attachment, intimacy and self-efficacy, is responsible for varied levels of psychological distress (Atibioke amd Osinowo, 2013), heightened levels of anxiety, poor emotional adaptation and increased or excessive substance use, most often coupled with exclusion and social isolation within family and in the neighbourhood (Rispel, et al., 2009; Collini and Obasi, 2006), more so among couples with unstable income (Reshmi \& Sekar, 2011) and those without sufficient family support (Elwin et.al, 2006 \& Eyavo et al, 2010).

Discordancy is reported to have caused marital separation and disruptions. Various studies have indicated that the evidently high risk of HIV sero-conversion and uncertainty of the uninfected couple's sero-status permanence have prompted discordant couples to difficulties related to sexual practices observed in distancing and avoidance of partner, which further elevate the tensions between worrying about being infected and keeping their sexual life active (Reis and Gir, 2010).
Despite all the uncertainties therewith, studies indicate that not all couples choose to separate or divorce; not all opt to bear the fear of the unthinkable danger to the negative couple: some have separated, some divorced, some have experienced weakened intimacy and sexual infidelity (Bunnell et al., 2011), some sustained a normal relation, some reported heightened levels of intimacy than ever before. Certainly, there are factors, be they social, psychological, socio-economic or cultural which determine the chances of infected couples fight (sustain) or flight (refrain from) the uneventful realities of discordancy.

\subsection{Psycho-social Issues Associated with HIV Sero-Discordance and Concordance}

HIV infection is a source of emotional and physiological stress (Faul-stich, 1987). The stress level of the person affected depends on their knowledge and skills, attachment to significant others, intimacy with their spouses and self-efficacy; when a person's stress condition is persistent, it adds up to increased symptomatology and hastens disease progression (Van Erk et al., 1996). Other studies have indicated heightened levels of anxiety, poor emotional adaptation, increased substance use, social isolation among HIV infected couples (Rispel et al., 2009; Collini and Obasi, 2006; Eyayo et al., 2010), as well as distancing and sexual avoidance (Reis and Gir, 2010). These conditions, however, as observed by Reshmi and Sekar, (2011), are more pronounced among couples with unstable income.

Despite the emotional and psychosocial responses described above, Bunnell, et al., (2005) who compared 49 positive concordant and 126 discordant couples in couple counselling in Kampala Uganda have a rather astounding observation. Their findings reveal that partners in a positive concordant relationship were more likely to be living together than those in a discordant relationship. This is exhibited in higher separation, infidelity, lack of social support and divorce rates among discordant couples, compared to those in a seroconcordant relationship. Nevertheless, little is known on the extent to which concordant couples differ from discordant couples in their emotional responses to psychosocial challenges.

Two major issues are noted as significant following these revelations; first, the negative 
partner in a discordant relationship is constantly in fear of the adverse risk of catching the virus from partner, thus, only a few of them are more or less likely to carry on with a functional relationship. Second, relationship instability and sexual avoidance among discordant couples may substantially attract extramarital relationships coupled with inconsistent condom use (Mujugira, Baeten, Donnell, Ndase, Mugo et al., 2011), which may be responsible for further infections (of others).

These findings significantly point out to the fact that there is a need for married or cohabiting heterosexual couples to be mainstreamed within the broader prevention framework. That has been practiced in the developed countries, including the use of Pre-Exposure Prophylaxis (PrEP), or use of condom which is a commonly used measure but with a lot of challenges on consistence. PrEP was initially introduced among homosexual men with unlike serostatuses in the U.S by the United States Centre for Disease Control in 2011. UNAIDS, (2013) reports a significant reduction in transmission of HIV among those who adhered to the therapy consistently, and the programme was thus adopted, in the U.S. for use among heterosexual couples in 2012. Access to such therapy would most likely be of similar effect among discordant couples, elsewhere.

When it is empirically established that new infections in a mature epidemic occur among discordant couples, understanding the dynamics of discordancy against those of concordancy may be key to mechanising practical intervention programmes to prevent infections among the negative partner in a discordant relationship (Bishop and Foreit, 2010). It is imperative therefore, to find out whether discordant couples share any distinguishing characteristics in their relationships, unlike those of concordant couples, which may improve intervention programmes such as effective couple counselling, treatment and care to prevent inter-couple HIV transmissions.

\subsection{HIV Sero-discordance and Emotional problems}

Reshmi and Sekar, (2011) suggest that emotional and psycho-social problems are more persistent among disenfranchised infected couples. This is indicative of gender-based determinants of the couple's marital ends which may include; ownership, education, decision making, self-efficacy, social support and power, lack of which may be exhibited with emotional and depression symptoms. This brought up the question; who exhibits more depressive symptoms between positive concordant and discordant couples, and why? The dynamics of infected couples, their distinguishing characteristics, their self-efficacy and individual psycho-social responses towards the concordant or discordant relationship very much determine how their relationships function (Merson, Dayton \& O'Reilly, 2000). However, what discordant couples consider the most important determining factors to their marital ends, following their knowledge of sero-magnetism, required a thorough investigation.

Other studies have looked into various aspects involving discordant couples such as stigma (Mujugira et al., 2011), weakened intimacy and sexual infidelity (Bunnell et al., (2008), distress, anxiety and depression (Reis, R.K and E. Gir, 2010; Hand, Phillip and Dudgeon, 2006) and high divorce and separation rates (Malamba et al., 2005), just to mention a few. However, very few of these studies have looked into the influence of sero-discordancy on family and couple relationship functioning and how it differs from that among concordant couples. Furthermore, little is known as to how resource access, both physical and psychosocial, influences the partner's appraisal of, and their ultimate decision on their discordant relationship.

\section{THEORETICAL FRAMEWORK}

Human life is composed with many challenges, internal and external, negative and delightful, immediate and delayed. The Lazarus and Folkman's (1984)'s Transactional Model asserts that individuals live in a continuum of transaction with the various settings in which they spend time, running their day to day life (Bloom, 1996). In this transaction, individuals relate with the environment, their significant others, and institutions. While transacting, people meet situations, such as knowledge of their HIV infection, which create demands upon them. These demands become challenges and can create stress (Mujugira et al., 2011; Lewis, 1998) In this view, any situation characteristics of stressful experiences whose demands exceed the adaptive responses available in a given system are challenges (Selye, 1976). These challenges can become a stress to one person and strenuous to another at the same time 
(Bloom, 1996). Challenges are never-ending in life: some represent delightful situations that relish life, others push for adaptive responses beyond limit. Thus, when faced with challenges, individuals require a supplementary resource, be it physical, financial or psycho-social, so as to sustain a functional livelihood. In absence of these supplementary resources, a person may be lured into, and start to reveal physiological, physical or psychosocial symptomatology (Atibioke amd Osinowo, 2013). In other extreme situations an individual may die (Lewis, 1998).

According to Lewis, Sperry and Calson, (1993) and Lewis, (1998), the severity of how a person perceives a challenge, such as seroconcordancy or discordancy, as stressful depends on various factors, including one's own view of one's ability to handle new demands, previous success in dealing with similar situations, the degree to which one feels in control of events, one's perception of being overloaded or having conflicting needs and the standards one sets for one's own performance.

Essentially, coping decisions begin with a person perceiving an external factor which is independent of the actor as problematic (Lazarus \& Folkman, 1984; Bloom, 1996). A person's cognition of their cognitive difficulties and emotional burdens they experience determines not only what coping style they need to adopt, but also the severity of damage that is likely to face the person. Individuals' perception and evaluation of a stressful and challenging situation is primary and vital in the whole process of decision making. Lazarus and Folkman call this-situational appraisal. A person's appraisal of being an infected couple shapes one's view of the severity of the problem and a kind of coping styles they may need to take, which are specific to that challenge (Lazarus \& Folkman 1986).

Nearly all cognitions and perceptions are evaluative; rarely do people see things without evaluating them (Markus \& Zajonc, 1985). The concept of appraisal further explains individual differences in perception, evaluation, perceived severity and intensity of consequent physiological responses, as well as the uniqueness of the coping strategy a person is likely to choose in the course of action. In that, though all people can appraise and evaluate situations, they will not do so impulsively and habitually. There are individual differences in the tendency to engage in evaluation (Franzoi, 2000). This also results in the difference in the decisions infected couples make to the ends of their relationships, and how their relationship functions thereafter. In other words, the couples' appraisal and evaluation of the discordant situation determines whether the situation represents harm or loss, viewed as threat to one's well-being or merely delightful an episode in one's life (Lazarus, 1980).

Explaining other significant differences in appraising and evaluating, Janis, (1958) posits that a person's appraisal is influenced by a couple of factors, including one's personal morale or efficacy, motivation, values and culture, resource accessibility and situational factors. In his view, Janis believes that situational factors encompass predictability, manageability and severity of a stressful situation such as discordancy and concordancy. So, having perceived a sero-discordant situation as problematic, analysed and evaluated it as threat or loss, harmful or delightful, an infected couple enters into a second stage of coping, namely determining the cause of action. In this stage, the individual decides which action to take-fight or flight, and what kind of supplementary resources are needed and available (Lewis, 1998; Janis, 1958; Bloom, 1996).

Thus, people develop a typical style of adapting also known as coping style. The Lazarus and Folkman, (1984)'s transactional model distinguishes two aspects of coping, namely, problem-focused coping and emotion-focused or palliative coping. Problem-focused coping refers to an effort to make such changes in persons, objects or relationships so as to resolve the stressful challenge. For instance, a sero-positive discordant couple's husband may choose to abstain from sex with spouse so as to avoid her possible sero-conversion.

On the other hand, emotion-focused or palliative coping refers to thoughts or actions whose goal is to reduce the emotional effect of a stressful challenge, which appears in physiological disturbances (Lewis, 1998; Hand, 2006). So while problem-focused coping depends on resources availability, and external objects, emotion-focused coping depends on cognitive and emotional state of the actor. The current 
study model has borrowed immensely from the Transactional Model.

Borrowing from the Lazarus and Folkman, (1984)'s Transaction Model, the proposed model for this study assumed that socioeconomic resources, on one hand, and psycho-social on the other are independent variables mediated by the concordant or discordant partner's status and coping strategies. Marital resolution encompasses the dependent variables. It was thought that understanding what motivates infected couples to decide on their marital ends have got a lot to do with the external and internal forces around them, how they appraised their HIV situation, the extent and amount of resources they required and those availed to them, self-efficacy, psycho-social skills they have attained and their ability to reason out their actions and the ultimate decisions towards their marital relationships fate.

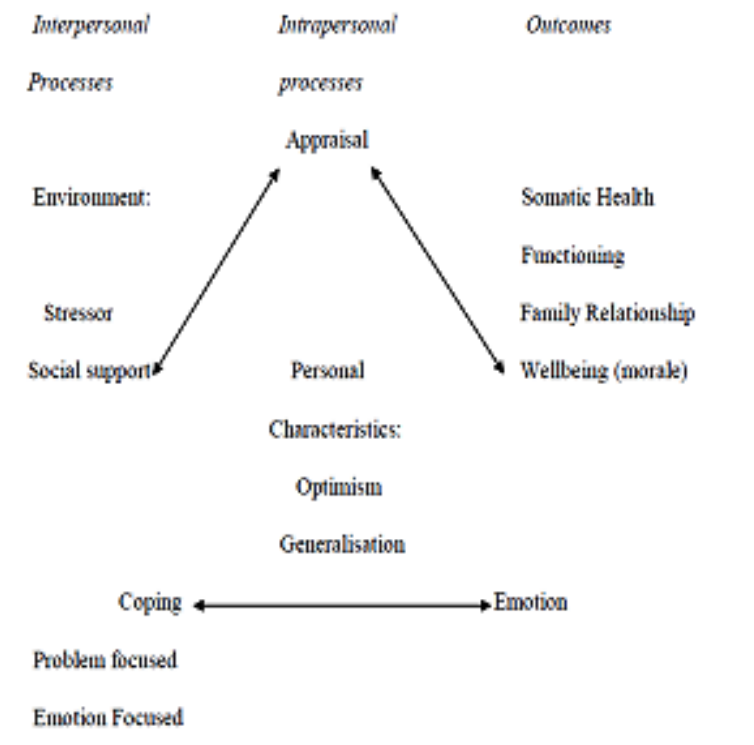

Figure1: The Lazarus and Folk man (1984)'s transactional Model From "Stress, Appraisal and Coping” by Lazarus and Folk man, 1984

Whereas discordancy is associated with increased distress, anxiety, depression, seroconversion and poor emotional adaptation (Atibioke amd Osinowo, 2013; Carpenter et al., 2011), Malamba et al., (2005) and Reshmi and Sekar, (2011) observe that this is more severe among disenfranchised couples. In this view, infected couples' access to resources is likely to influence their health and emotional wellbeing. Thus, the individuals' ability to appraise their sero-discordancy is primarily influenced by their physical and financial, on one hand, and psychosocial on the other. And that the availability of these resources favours an individual regardless of their status. The individual's access to socio-economic and psychological resources determines their rational attribution of discordancy and the outcome of their coping is a product of a calculated transaction with the available resources.

Discordancy have been associated with more difficulties as compared to the concordant couples, these include relationship and emotional disturbances, sexual contact distancing, marital separation and disruptions. The Lazarus and Folkman's (1984)'s Transactional Model can be helpful in understanding individuals with HIV discordancy on their emotional response, coping strategies and the ultimate decisions towards their marital relationships fate.

\section{REFERENCES}

[1] Allen, S., Karita, E., Chomba, E., Roth, D. L., Telfair, J., Zulu, I. and Haworth, A. (2007), Promotion of Couples' Voluntary Counselling and Testing for HIV Through Influential Networks in Two African Capital Cities. BMC Public Health, 7, 349.

[2] Allen, S., Meinzen-Derr, J., Kautzman, M., Zulu, I., Trask, S., Fideli, U. And Haworth, A. (2003), Sexual Behavior of HIV-discordant Couples after HIV Counselling and Testing. AIDS (London, England), 17(5), 733-740.

[3] Atibioke, P., \& Osinowo, O. (2013), Psychological Trauma Following Disclosure of HIV Status to Significant Others in Women Living With HIV and AIDS, Research on Humanities and Social Sciences. 3(1), 156161.

[4] Bishop, M and Foreit, K., (2010), Serodiscordant Couples in Sub-Sahara Africa: What do the Survey Data Tell Us? Washington, DC: Future Group, Health Policy Initiative, Task Order 1.

[5] Bloom, M. (1996), Primary Prevention Practices.Thousands Oaks. CA: SAGE.

[6] Brubaker, S. G., Bukusi, E. a., Odoyo, J., Achando, J., Okumu, A., and Cohen, C. R. (2011), Pregnancy and HIV Transmission among HIV-discordant Couples in a Clinical Trial in Kisumu, Kenya. HIV Medicine, 12(5), 316-321. http://doi.org/10.1111/j.1468-1293. 2010. 00884.x.

[7] Bruyn, G., Badenzi, N., Dladla, S. and Gray, G. (2006), HIV-Discordant Couples: an Emerging Issue in Prevention and Treatment. The South African Journal of HIV Medicine, 12, 25-28.

[8] Bujan, L., Hollander, L., Coudert, M., GillingSmith, C., Vucetich, A., Guibert, J., and 
Semprini, A. E. (2007), Safety and Efficacy of Sperm Washing in HIV-1-Serodiscordant Couples Where the Male is Infected: Results from the European CREAThE Network. AIDS (London, England), 21(14), 1909-1914. http://doi.org/10.1097/QAD.0b013e328270387 9.

[9] Campbell, M. S., Mullins, J. I., Hughes, J. P., Celum, C., and Lingappa, J. R. (2011), Viral Linkage in HIV-1 Seroconverters and their Partners in an HIV-1 Prevention Clinical Trial. PLoS ONE, 6(3).

[10] Carpenter, Lucy M. Anatoli Kamali, Anthony Ruberantwari, Samuel S. Malamba and James A.G. Whitworth, (1999), Rates of HIV-1 Tansmission within Marriage in Rural Uganda in Relation to the HIV Sero-status of the Partners, AIDS, 13: 1083- 1089.

[11] Carver, C. S., Scheier, M. F., and Weintraub, J. K. (1989), Assessing Coping Strategies: a Theoretically Based Approach. Journal of Personality and Social Psychology, 56(2), 267283.

[12] Chavan et al, 2014; Chavan, V. R., Chaudhari, D., Ahir, S., Ansari, Z., Mehta, P., \& ManiaPramanik, J. (2014). Variations in KIR genes: A study in HIV-1 serodiscordant couples. BioMed Research International, 2014.

[13] Chemaitelly, H., Awad, S. F., \& Abu-raddad, L. J. (2017), The risk of HIV transmission within HIV-1 sero-discordant couples appears to vary across sub-Saharan Africa. Epidemics, 6(2014), $1-9$. http://doi.org/10.1016/j.epidem.2013.11.001.

[14] Chemaitelly, H., Cremin, I., Shelton, J., Hallett, T. B., \& Abu-raddad, L. J. (2012). Distinct HIV discordancy patterns by epidemic size in stable sexual partnerships in sub-Saharan Africa, 51$57 . \quad$ http://doi.org/10.1136/sextrans-2011050114

[15] Chen, JL, Phillip, KA, Kanouse, DE, Collins, RL and Miu, A, (2001), Fertility Desires and Intentions of HIV-Positive Men and Women. Family Planning Perspectives. 33:144-152.

[16] Chomba, E., Allen, S., Kanweka, W., Tichacek, A., Cox, G., Shutes, E., Haworth, A. (2008). Evolution of couples' voluntary counseling and testing for HIV in Lusaka, Zambia. Journal of Acquired Immune Deficiency Syndromes, 47(1), 108-115. http://doi.org/10.1097/QAI.0b013e31815b2d67

[17] Cohn, S. K., and Weaver, L. T. (2006), The Black Death and AIDS: CCR5-Delta-32 in Genetics and History. Qjm, 99(8), 497-503.

[18] Collini, P. and Obasi, A. (2006), Interventions to Reduce HIV Sexual Transmission within Discordant Couples. BMJ Publishing Group Limited.
[19] De Walque, D. (2006), Discordant Couples: HIV Infection among Couples in Burkina Faso, Cameroon, Ghana, Kenya, and Tanzania." Policy Research Working Paper Series 3956. Washington, DC: World Bank.

[20] Desgrées-du-Lô̂, A., \& Orne-Gliemann, J. (2008). Couple-centred testing and counselling for HIV serodiscordant heterosexual couples in sub-Saharan Africa. Reproductive Health Matters, 16(32), 151-161.

[21] Desgrées-du-Loû, A., and Orne-Gliemann, J. (2008), Couple-centred Testing and Counselling for HIV Serodiscordant Heterosexual Couples in Sub-Saharan Africa. Reproductive Health Matters, 16(32), 151-161.

[22] Downs, A. M., and De Vincenzi, I. (1996), Probability of Heterosexual Transmission of HIV: Relationship to the Number of Unprotected Sexual Contacts. European Study Group in Heterosexual Transmission of HIV. Journal of Acquired Immune Deficiency Syndromes and Human Retrovirology: Official Publication of the International Retrovirology Association, 11(4), 388-395.

[23] Dunkle, K.L., R. Stephenson, E. Karita, E. Chomba, K. Kayitenkore, C. Vwalika, L. Greenberg, and S. Allen. (2008), "New Heterosexually Transmitted HIV Infections in Married or Cohabitating Couples in Urban Zambia and Rwanda: An Analysis of Survey and Clinical Data." Lancet 371(9631): 218391.

[24] Elwin Wu, Nabila El-Bassel, DSW, Louisa Gilbert, MS, and Pamela Morse, MS. (2006), Dyadic HIV Status and Psychological Distress among Women on Methadone. Women's Health Issues. New York, Vol.16, 113-121.

[25] Eyawo, O., de Walque, D., Ford, N., Gakii, G., Lester, R. T., and Mills, E. J. (2010), HIV Status in Discordant Couples in Sub-Saharan Africa: a Systematic Review and Metaanalysis. The Lancet Infectious Diseases, 10(11), 770-777.

[26] Faulstich, M. (1987), Psychiatric Aspects of Aids, American Journal of Psychiatry, 144, 551-556.

[27] Fishel, J. D., Bradley, S. E., Young, P. W., Mbofana, F., \& Botao, C. (2011). HIV among Couples in Mozambique: HIV Status, Knowledge of Status, and Factors associated with HIV Serodiscordance. Further analysis of the 2009 Inquérito Nacional de Prevalência, Riscos Comportamentais e Informação sobre o HIV e SIDA em Moçambique 2009.

[28] Franzoi, S. (2000), Social Psychology. ( $2^{\text {nd }}$ ed).Boston: Mc Graw - Hill.

[29] Gitonga, M., Ballidawa, J., \& Ndege, S. (2012), Challenges and coping strategies among couples of mixed HIV status presenting at a 
large comprehensive care centre in Eldoret, Kenya. Journal of Biology, Agriculture and Healthcare, 2(8), 18-27. Retrieved from http://www.iiste.org/ Journals/index.php/ $\mathrm{JBAH} /$ article/view/2858.

[30] Glanz, K. (1997), Health Behaviour and Health Education: Theory, Research and Practice. San Fransisco, CA: Jossy-Bass.

[31] Grabowski, M. K., Lessler, J., Nalugoda, F., Reynolds, S. J., Ssekubugu, R., Kong, X., Gray, R. H. (2014). Introduction of HIV into Stable Heterosexual Couples in Rakai, Uganda Before and After ART. CROI 2014, abstract 1.

[32] Gray, R. H., Kigozi, G., Serwadda, D., Makumbi, F., Watya, S., Nalugoda, F., Wawer, M. J. (2007). Male circumcision for HIV prevention in men in Rakai, Uganda: a randomised trial. Lancet, 369(9562), 657-666. http://doi.org/S0140-6736(07)60313-4 [pii] Ir10.1016/S0140-6736(07)60313-4 [doi]

[33] Gray, R. H., Wawer, M. J., Brookmeyer, R., Sewankambo, N. K., Serwadda, D., WabwireMangen, F., ... Quinn, T. C. (2001). Probability of HIV-1 transmission per coital act in monogamous, heterosexual, HIV-1-discordant couples in Rakai, Uganda. Lancet, 357(9263), 1149-1153.

[34] Guthrie, B. L., de Bruyn, G., \& Farquhar, C. (2007). HIV-1-discordant couples in subSaharan Africa: explanations and implications for high rates of discordancy. Current HIV Research, 5(4), 416-429.

[35] Hand, G. A., Phillips, K. D., \& Dudgeon, W. D. (2006). Perceived stress in HIV-infected individuals: Physiological and psychological correlates. AIDS Care, 18(8), 1011-1017. http://doi.org/10.1080/09540120600568376.

[36] Hira, S.K., Feldblum, P.J., Kamanga, J., Mukelabai, G., Weir, S.S., Thomas, J.C., 1997.Condom and nonoxynol-9 use and the incidence of HIV infection in serodiscor-dant couples in Zambia. Int. J. STD AIDS 8 (4), 243-250.

[37] Idele, P., Gillespie, A., Porth, T., Suzuki, C., Mahy, M., Kasedde, S., \& Luo, C. (2014). Epidemiology of HIV and AIDS among Adolescents: Current Status, Inequities, and Data Gaps, 66, 144-153.

[38] IRIN/PLUS NEWS, (2008), Supporting Discordant Couples to Stay Together. Retrieved on 6/10/2012 from http://www.plusnews.org/ Report.aspx? ReportId=73468.

[39] Janis, I. L. (1958), Psychological Stress: Psychoanalytic and Behavioral Studies of Surgical Patients. New York: Wiley.

[40] Kaiser, R., Bunnell, R., Hightower, A., Kim, A. A., Cherutich, P., Mwangi, M., and Mermin, J. (2011), Factors Associated with HIV Infection in Married or Cohabitating Couples in Kenya:
Results from a Nationally Representative Study. PLoS ONE, 6(3).

[41] Kimanga, D. O., Ogola, S., Umuro, M., Ng'ang'a, A., Kimondo, L., Murithi, P., Group, for the K. S. (2014). Prevalence and Incidence of HIV Infection, Trends, and Risk Factors among Persons Aged 15-64 Years in Kenya: Results from a Nationally Representative Study. JAIDS Journal of Acquired Immune Deficiency Syndromes, 66, S13-S26 10.1097/QAI.0000000000000124. Retrieved from

http://journals.lww.com/jaids/Fulltext/2014/050 11/Prevalence_and_Incidence_of_HIV_Infectio n,_Trends,.3.aspx

[42] Kumar, V., Prakash, O., Manpreet, S., Sumedh, G., \& Medhi, B. (2006). Genetic basis of HIV-1 resistance and susceptibility: An approach to understand correlation between human genes and HIV-1 infection, 44(September), 683-692.

[43] Kumarasamy, N., Venkatesh, K. K., Srikrishnan, a. K., Prasad, L., Balakrishnan, P., Thamburaj, E., ... Mayer, K. (2010). Risk factors for HIV transmission among heterosexual discordant couples in South India. HIV Medicine, 11(3), 178-186. http://doi.org/10.1111/j.14681293.2009.00760.x

[44] Lazarus, R. S \& Folkman, S. (1984). Stress, Appraisal and Coping. New york: Spring Bublishing Company.

[45] Lazarus, R. S and Folkman, S. (1984), Stress, Appraisal and Coping. New york: Spring Publishing Company.

[46] Lazarus, R. S, and Folkman, S. (1986), Dynamics of a Stressful Encounter: Cognitive Appraisal, Coping and Encounter Outcome. Journal of Personality and Social Psychology, 50, $992-1063$.

[47] Lewis, J. A. (1998).Community Counselling: Empowerment for a Diverse Society. Washington: Brooks / Cole Publishing Company.

[48] Lewis, J. A., Sperry, L. and Carlson. (1993), Health Counselling. Pacific Grove CA:Brookes/Cole.F.

[49] Lingappa, J. R., Lambdin, B., Bukusi, E. A., Ngure, K., Kavuma, L., Inambao, M., Rees, H. (2008). Regional differences in prevalence of HIV-1 discordance in Africa and enrollment of HIV-1 discordant couples into an HIV-1 prevention trial. PLOS ONE, 3(1).

[50] Lurie, M. N., Williams, B. G., Zuma, K., Mkaya-mwamburi, D., Garnett, G. P., Sturm, A. W., ... Karim, S. S. A. (1886). The Impact of Migration on HIV-1 Transmission in South Africa A Study of Migrant and Nonmigrant Men and Their Partners. 
[51] MacKelprang, R. D., Baeten, J. M., Donnell, D., Celum, C., Farquhar, C., De Bruyn, G., ... Lingappa, J. R. (2012). Quantifying ongoing HIV-1 exposure in HIV-1-serodiscordant couples to identify individuals with potential host resistance to HIV-1. Journal of Infectious Diseases, 206(8), 1299-1308.

[52] Malamba, S. S., Mermin, J. H., Bunnell, R., Mubangizi, J., Kalule, J., Marum, E., and Downing, R. (2005), Couples at Risk: HIV-1 Concordancy and Discordancy among Sexual Partners Receiving Voluntary Counselling and Testing in Uganda. Journal of Acquired Immune Deficiency Syndromes (1999), 39(5), 576-580.

[53] Malamba, S. S., Mermin, J. H., Bunnell, R., Mubangizi, J., Kalule, J., Marum, E., ... Downing, R. (2005), Couples at risk: HIV-1 concordance and discordance among sexual partners receiving voluntary counseling and testing in Uganda. Journal of Acquired Immune Deficiency Syndromes (1999), 39(5), 576-580.

[54] Maman, S., Mbwambo, J. K., Hogan, N. M., Kilonzo, G. P., Campbell, J. C., Weiss, E., \& Sweat, M. D. (2002), HIV-positive women report more lifetime partner violence: findings from a voluntary counseling and testing clinic in Dar es Salaam, Tanzania. American Journal of Public Health, 92(8), 1331-1337.

[55] Mandelbrot, L., Head, I., Henrion-Geant, E. and Henrion, R., (1997), Natural Conception in HIV-negative Women with HIV-infected Partners (letter). Lancet 349, 850-851.

[56] Marfatia, Y. S., Naik, E., Singhal, P., \& Naswa, S. (2013). Profile of HIV seroconcordant/ discordant couples a clinic based study at Vadodara, India. Indian Journal of Sexually Transmitted Diseases, 34(1), 5-9. http://doi.org/10.4103/0253-7184.112862.

[57] Markus, H. \& Zanjonc, R. (1985). The Cognitive Perspective in Social Psychology. In G. Lindzy and E. Aronson (Eds), Handbook of Social Psychology. Hillsdale,NJ: Erlbaum.

[58] Mastro, T. and De Vicenzi, I. (1996), Probabilities of Sexual HIV Transmission. AIDS: 10, 575-582.

[59] Matovu, J. K. B. (2010). Preventing HIV transmission in married and cohabiting HIVdiscordant couples in sub-Saharan Africa through combination prevention. Current HIV Research, 8(6), 430-440.

[60] Matovu, J. K. B. (2010). Preventing HIV transmission in married and cohabiting HIVdiscordant couples in sub-Saharan Africa through combination prevention. Current HIV Research, 8(6), 430-440.

[61] Melo, M. G., Santos, B. R., De Cassia Lira, R., Varella, I. S., Turella, M. L., Rocha, T. M., and Nielsen-Saines, K. (2008), Sexual Transmission of HIV-1 among Serodiscordant Couples in Porto Alegre, Southern Brazil. Sexually Transmitted Diseases, 35(11), 912-915.

[62] Merson, M.H., Dayton, J.M., \& O'Reilly, K. (2000), Effectiveness of HIV Prevention Interventions in Developing Countries. AIDS, 14 suppl 2, S68-S84.

[63] Mugo, N. R., Heffron, R., Donnell, D., Wald, A., Were, E. O., Rees, H., and Baeten, J. M. (2011), Increased Risk of HIV-1 Transmission in Pregnancy: a Prospective Study among African HIV-1-Serodiscordant Couples. AIDS (London, England), 25(15), 1887-95. Retrieved from http:// www. pubmedcentral.nih.Gov/ articlerender.fcgi? artid=3173565\&tool=pmcent rez\&rendertype $=$ abstract.

[64] Mugwanya, K. K., Baeten, J. M., NakkuJoloba, E., Katabira, E., Celum, C., Tisch, D., and Whalen, C. (2010), Knowledge and Attitudes about Male Circumcision for HIV-1 Prevention among Heterosexual HIV-1 Serodiscordant Partnerships in Kampala, Uganda. AIDS and Behavior, 14(5), 11901197.

[65] Mujugira, A., Baeten, J. M., Donnell, D., Ndase, P., Mugo, N. R., Barnes, L., and Celum, C. (2011a), Characteristics of HIV-1 Serodiscordant Couples Enrolled in a Clinical Trial of antiretroviral Pre-Exposure Prophylaxis for HIV-1 Prevention. PLoS ONE, 6(10).

[66] National Bureau of Statistics (2013), The HIV/AIDS and Malaria Indicator Survey 201112. Tanzania; NBS

[67] Novembre, J., Galvani, A. P., and Slatkin, M. (2005), The Geographic Spread of the CCR5Delta-32 HIV-Resistance Allele. PLoS Biology, 3(11), 1954-1962. http://doi.org/10. 1371/journal.pbio.0030339.

[68] Nutbean, K and Harris, T. (1998), Theory in a Nutshell. Thousand Oaks CA:

[69] Pancino, G., Saez-Cirion, A., Scott-Algara, D., \& Paul, P. (2010). Natural resistance to HIV infection: lessons learned from HIV-exposed uninfected individuals. The Journal of Infectious Diseases, 202 Suppl, S345-S350.

[70] Peter Gordon, \& Kate Crehan. (2000). Dying of Sadness: Gender, Sexual Violence and the HIV Epidemic. Social Development and Poverty Elimination Division (SEPED) Conference, (December 1997). Retrieved from http://www.genderandaids.org/index.php?optio $\mathrm{n}=$ com_content $\&$ view=article $\& \mathrm{id}=438$ :dyingof-sadness-gender-sexual-violence-and-the-hivepidemic \&catid=62: violence-against-womenand-hivaids \&Itemid=104.

[71] Quinn TC, Wawer MJ, Sewankambo N, Serwadda D and Li C. (2000), Viral Load and Heterosexual Transmission of Human 
Immunodeficiency Virus Type 1. Rakai Project Study Group. N Engl J Med 342: 921-929. 16.

[72] Ramsahoye, B., Collins, P., Davies. N. and Walkers, H. (1998), Family Planning in the Shadow of HIV Infection. Haemophilia, 4, 316320.

[73] Reis, R. K., and Gir, E. (2010), [Living with the Difference: the Impact of Sero-discordancy on the Affective and Sexual Life of HIV/AIDS Patients]. Revista Da Escola de Enfermagem Da U S P, 44(3), 759-765.

[74] Reshmi George and K. Sekar. (2011), Psychosocial Profile of Widows Living with HIV/AIDS. Published in Identity Representations and Social Exclusion of Women in India: An Identity Discourse.

[75] Rispel, L., Metcalf, C., Moody, K., \& Cloet, A. (2009), Exploring Coping Strategies and Life Choices made by HIV Discordant Couples in Long Term Relationships: Insights from South Africa, Tnzania and Ukraine. Amsterdam, GNP+.

[76] Rispel, L., Metcalf, C., Moody, K., \& Cloet, A. (2009). Exploring Coping Strategies and Life Choices made by HIV Discordant Couples in Long Term Relationships: Insights from South Africa, Tnzania and Ukraine. Amsterdam, GNP+.

[77] Rochstroh, J.K., Ewig, S., Bauer, T., Luchters, G., Oldenburg, J., Bailly, E., Kaiser, R.,Scheweis, K.E., Brackmann, H.H., Dengler, H.J. and Sauerbruch, T., (1995), Male-tofemale Transmission of HIV in a Cohort of Haemophiliacs; Frequency, Risk Factors and Effect of Sexual Counselling. Infection, 23, 2932.

[78] Rojanawiwat, A., Ariyoshi, K., Pathipvanich, P., \& Tsuchiya, N. (2009). Substantially Exposed but HIV-Negative Individuals Are Accumulated in HIV-Serology-Discordant Couples Diagnosed in a Referral Hospital in Thailand, 32-36.

[79] Selye, H. (1976), The Stress of Life. New York: Mc Graw Hill.

[80] Smith, M. W., Dean, M., Carrington, M., Winkler, C., Huttley, G. A., Lomb, D. A., Hilgartner, M. W. (1997). Contrasting Genetic Influence of CCR2 and CCR5 Variants on HIV-1 Infection and Disease Progression, 277(August).

[81] Tam, V. Van, Cuong, D. D., Alfven, T., Phuc, H. D., Thi, N., Chuc, K., Larsson, M. (2016). HIV sero - discordance among married HIV patients initiating anti - retroviral therapy in northern Vietnam. AIDS Research and Therapy, (March 2010), 1-7. http://doi.org/10.1186/s12981-016-0124-9
[82] Trask, S. A., Derdeyn, C. A., Fideli, U., Chen, Y., Meleth, S., Kasolo, F., ... Hahn, B. H. (2002), Molecular Epidemiology of Human Immunodeficiency Virus Type 1 Transmission in a Heterosexual Cohort of Discordant Couples in ... Molecular Epidemiology of Human Immunodeficiency Virus Type 1 Transmission in a Heterosexual Cohort of Discordant Couples in Zambia, (April). http://doi.org/10.1128/JVI.76.1.397.

[83] United Republic of Tanzania, (2013), The 2012 National Population and Housing Census. Dar es Salaam: Central Census Office.

[84] United Republic of Tanzania, (2013), 2011-12 HIV/AIDS and Malaria Indicator Survey. Dar es Salaam: Central Census Office.

[85] van Eck, M., Berkhof, H., Nicolson, N., \& Sulon, J. (1996), The effects of perceived stress, traits, mood states and stressful daily events on salivary cortisol. Psychosomatic Medicine, 58, 447? 458.

[86] Wall, K. M., Kilembe, W., Nizam, A., Vwalika, C., Kautzman, M., Chomba, E., ... Allen, S. (2012), Promotion of Couples' Voluntary HIV Counselling and Testing in Lusaka, Zambia by Influence Network Leaders and Agents. BMJ Open: 2.e001171. doi: 10. 1136/bmjopen-2012001171.

[87] Ware, N. C., Wyatt, M. A., Haberer, J. E., Baeten, J. M., Kintu, A., Psaros, C., and Bangsberg, D. R. (2012), What's Love Got to Do With It? Explaining Adherence to Oral Antiretroviral Pre-Exposure Prophylaxis for HIV-Serodiscordant Couples. JAIDS Journal of Acquired Immune Deficiency Syndromes.

[88] Wawer, M. J., Gray, R. H., Sewankambo, N. K., Serwadda, D., Li, X., Laeyendecker, O., and Quinn, T. C. (2005), Rates of HIV-1 Transmission per Coital Act, by stage of HIV-1 Infection, in Rakai, Uganda. The Journal of Infectious Diseases, 191(9), 1403-1409.

[89] WHO/UNAIDS, (2008), Global Report: UNAIDS Report on the Global AIDS Epidemic. Geneva.

[90] WHO/UNAIDS, (2012), Global Report: UNAIDS Report on the Global AIDS Epidemic. Geneva.

[91] WHO/UNAIDS, (2013), Global Report: UNAIDS Report on the Global AIDS Epidemic. Geneva.

[92] Wilde, J. (2002), Conception in HIVDiscordant Couples. Montreal, Quebec. Journal of World Federation of Haemophilia, 26, 1-11. Wiley and Sons, 2nd Edition.

[93] Yee,T., Goldman, E., Devereux, H., Sabin, C. and Lee,C.,(1999), Family Issues in HIV infected Haemophilic Patients.AIDS, 13,2314-5. 
Emotional and Relationship Dynamics between HIV Sero-Discordance and Concordance Couples: A Narrative Literature Review and Theoretical Framework

[94] Yin, R. (1989), Case Study Research: Design and Methods. Newbury CA: Sage.

[95] Zwolinska, K., Olga, B., Tomczyk, T., \& Knysz, B. (2016). The effects of killer cell immunoglobulin-like receptor ( KIR ) genes on susceptibility to HIV-1 infection in the Polish population,

327-337.
[96] Louisirirotchanakul, S., Roongpisuthipong, A., Poonarkngeng, R., \& Chaiyakool, P. (2001). Virological , Immunological and Host Factors in HIV-1 Discordant Couples in, 259-265.

Citation: Amani Mwakalapuka, Ipyana Mwampagatwa, Theodora Bali, Masumbuko Mwashambwa, Stephen Kibusi, Tumbwene Mwansisya, Emotional and Relationship Dynamics between HIV SeroDiscordance and Concordance Couples: A Narrative Literature Review and Theoretical Framework. ARC Journal of Public Health and Community Medicine. 2017; 2(2):1-14. doi:dx.doi.org/10.20431/24560596.0202001 .

Copyright: (c) 2017 Authors. This is an open-access article distributed under the terms of the Creative Commons Attribution License, which permits unrestricted use, distribution, and reproduction in any medium, provided the original author and source are credited. 